\title{
Artifacts and the Academic Motivation of African American Male Athletes
}

\author{
Eric Bailey \\ University of Memphis \\ Rhema Fuller \\ University of Memphis
}

Abstract: This case study sought to examine the academic motivations of African American male college athletes at a historically Black college and university (HBCU). Self-determination theory (SDT) was incorporated as the theoretical framework. Data were collected via artifacts from seven African American male college athletes at a HBCU in the mid-southern region of the United States. Explanation of the artifacts by the participants revealed that they were motivated by their family, their faith, and their resiliency. Findings, and their implications for research and practice, are discussed and presented.

Keywords: college athletics, motivation, African American, HBCU, academics

The intersection of race and ethnicity, higher education, and athletics continues to be a topic of interest for scholars and practitioners. In particular, greater attention is being given to the (negative) experiences of African American males by scholars, practitioners, and policy makers, among others (Blank, Sweeney, \& Fuller, 2014; Harrison, Martin, \& Fuller, 2015; Singer, 2005). Though insightful, the current discourse surrounding African American male college athletes is limited in at least two ways. First, scholars have noted a dearth of examination of the experiences of African American male college athletes in contexts beyond the National Collegiate Athletic Association (NCAA) Division I (DI) predominately White institutional (PWI) context (Harrison et al., 2015). This means that what is known about African American male college athletes is based on a nearly single contextual setting. Second, the most common methods to glean data from and about this demographic group are individual interviews, focus groups (e.g., Cooper \& Hawkins, 2012; Harrison et al., 2015; Singer, 2005) and surveys (e.g., Cooper \& Hall, 2014; Fuller, 2013). Despite the utility of such data collection methods, alternative research approaches are needed to yield more insightful perspectives into the lived experiences of these individuals because "what people say" is quite different from "what people do" (Hodder, 1994, p. 113). For this reason, the purpose of this case study was to utilize an innovative research design to examine the experiences of African American male college athletes beyond the NCAA DI PWI context. Specifically, this study used artifactual analysis (Hodder, 1994) to identify the academic motivations of African American male college athletes at a NCAA Division II (DII) historically Black college and university (HBCU). In doing so, implications for both practitioners and researchers are identified and presented. 


\section{Literature Review}

\section{African American Male Athletes and HBCUs}

There is a limited, but growing, number of studies that have examined the experiences of African American male athletes at HBCUs (Cooper, 2013; Cooper \& Hall, 2014; Cooper \& Hawkins, 2012). In general, these studies have concluded that HBCUs are more conducive to the academic enrichment of African American male college athletes than predominately White institutions (PWIs). For example, Cooper (2013) examined the institutional culture of one HBCU and found that its athletic program was grounded in three basic assumptions: (a) athletes are students first, (b) holistic development of athletes is paramount, and (c) the institution operated as an extension of the African American community. Based on these three assumptions, the culture at this HBCU cultivated a positive educational environment for its college athletes (Cooper, 2013). Likewise, Cooper and Hall (2014) reported that HBCUs had strong nurturing environments for their athletes. In particular, faculty were instrumental in creating a familial atmosphere at the HBCUs. Moreover, HBCUs have been identified as a place of opportunity that challenges students academically and enhances their academic self-efficacy and social life (Cooper \& Hawkins, 2012). While the aforementioned research has been instrumental in identifying how macro-level factors (e.g., the institutional environment) foster the experiences of individuals at HBCUs, little is known about the role that micro-level factors play. Understanding what motivates individuals towards academic success is paramount if there is to be a more robust understanding of the utility of HBCUs in the lives of African American athletes (Cooper, 2013; Cooper \& Hall, 2014). Accordingly, self-determination theory (SDT) (Deci \& Ryan, 2000; 2002) was adopted as the theoretical framework for this study, as it can allow for a better understanding of the academic motivations of African American male athletes attending HBCUs.

\section{Self-Determination Theory}

As a macro-theory of motivation, SDT attempts to explain how the confluence of extrinsic and intrinsic factors motivate human beings towards behavior and action. In doing so, the theory postulates that humans are inherently motivated through self-determined actions (Deci \& Ryan, 2000; 2002). Such self-motivation, however, is influenced by both extrinsic and intrinsic factors. In general, three basic psychological needs are believed to influence motivation: (a) competence, (b) autonomy, and (c) relatedness (Deci \& Ryan, 2000; 2002). Motivation is likely to be cultivated when an individual's sense of competence, autonomy, and relatedness are supported (Deci \& Ryan, 2000; 2002). In contrast, motivation is believed to be impeded when either of these psychological needs (i.e., competence, autonomy, and relatedness) are absent or hindered (Deci \& Ryan, 2000).

SDT has been used in a variety of domains and contexts including physical activity and exercise (Hagger \& Chatzisarantis, 2007) and education (Cokley, 2003; Harrison et al., 2015). Relevant to the current study, SDT has been applied in prior studies to examine the educational experiences of African American students and athletes. For example, Cokley (2003) used SDT to challenge the perception that African American students are anti-intellectual. In doing so, he found that African American students attending HBCUs had higher levels of intrinsic motivation than their counterparts attending PWIs. Likewise, Harrison et al. (2015) utilized SDT to understand the 
academic persistence of high-achieving African American male scholar-athletes at academically rigorous institutions of higher education. The authors found that relatedness, in the form of peer support, was a significant influence on the self-determined motivation of the participants. Moreover, participants questioned their competence when they received negative feedback, which primarily came from coaches and poor grades. Consequently, their motivation towards academic achievement was hindered. Given the tenets of SDT, as well as findings from the relevant research (Cokley, 2003; Harrison et al., 2015), the central questions to the current case study were:

Research questions. What motivates African American athletes at HBCUs? Specifically, how salient is autonomous motivation, both intrinsic and extrinsic, to the academic success of these individuals?

\section{Method}

\section{Research Design}

As part of a larger study, a qualitative case study was used to understand the experiences associated with and related to the purpose of this study. A qualitative approach was implemented because it allows researchers to collect detailed data to tell the story of participants and understand how they construct meaning from their academic motivations (Merriam, 2009). Additionally, a case study provides an effective research design to understand the complexities of a given phenomenon and can lead to novel and intriguing findings (Eisenhardt, 1989). Though case studies have limited generalizability, scholars and practitioners can develop a greater understanding of participants' experiences from case studies - which can then assist in theory development and explication (Agyemang, Berg, \& Fuller, 2018; Stebbins, 2006).

For this case study, artifactual analysis was used to examine the academic motivation of African American male athletes at HBCUs (Hodder, 1994). Artifactual analysis is a research methodology by which artifacts serve as the primary source of data. Examples of artifacts include tools, books, utensils, pictures, photographs, and any other instrument of everyday living (Merriam, 2009). According to Hodder (1994), the analysis of artifacts as a data source is vastly important to generating knowledge. This is because interviews, which inform the majority of qualitative research, rely exclusively on what individuals report. Yet, "what people say" is quite often very different from "what people do" (Hodder, 1994, p. 113). Thus, artifactual analysis has the ability to produce alternative perspectives and provide insight at a greater depth than traditional qualitative research methodologies.

\section{Research Context}

The study was conducted on the campus of a NCAA DII HBCU in the mid-southern region of the United States. For the purposes of this study, the college was assigned a pseudonym and from hereon, will be referred to as Mid-South Historically Black College (MSHBC). MSHBC is a four-year private institution located in an urban metropolitan area in the southeastern region of the U.S. There were 959 total students enrolled during the 2015-16 academic school year. Approximately $67 \%$ of the students were female, and males consisted of $33 \%$. The average ACT 
score for entering freshmen was 15 and the retention rate was $50 \%$. The graduation rate for MSHBC was $14 \%$.

\section{Participants and Procedures}

Purposive sampling was utilized to recruit seven $(\mathrm{N}=7)$ African American male athletes who attended MSHBC. Although Creswell (2007) recommends no more than four to five participants for case study research, seven participants were used to provide a more robust sampling. Participants were selected with the assistance and approval from the athletic director and the athletes' coaches. An initial consultation with the athletic administrators and coaches from the institution took place to introduce the focus of the study and to identify African American male athletes who might be willing to participate. Consent to participate in the research study was presented to each athlete upon initial interaction. Participation in this study was on a voluntary basis.

As previously indicated, seven African American male athletes consented to participate in the study. Pseudonyms were assigned to each participant to protect their identities and to ensure compliance in accordance with the Institutional Review Board (IRB) policies. With respect to demographic information, the average age of each participant was 23 years old. Three participants were academically classified as juniors, two were classified as seniors, and two were graduating at the time of the data collection. In terms of sport, four participants participated in basketball and three participants played baseball. Table 1 provides a profile of each participant.

Table 1

Participant Profile

\begin{tabular}{|c|c|c|c|c|c|}
\hline Participant & Age & Major & Classification & Sport & Artifact \\
\hline Luke & 23 & Education (K-12) & $\begin{array}{l}\text { Graduating } \\
\text { Senior }\end{array}$ & Basketball & Bible \\
\hline Tinker & 23 & $\begin{array}{l}\text { Information } \\
\text { Technology }\end{array}$ & $\begin{array}{l}\text { Graduating } \\
\text { Senior }\end{array}$ & Basketball & $\begin{array}{l}\text { Obituary and Picture } \\
\text { of Deceased Relative }\end{array}$ \\
\hline Brian & 25 & Criminal Justice & Senior & Basketball & $\begin{array}{l}\text { Military Dog Tags } \\
\text { with Inscription }\end{array}$ \\
\hline Vince & 24 & Criminal Justice & Junior & Basketball & $\begin{array}{l}\text { Picture of Self and } \\
\text { Deceased Father }\end{array}$ \\
\hline Billy & 22 & Special Education & Senior & Baseball & Baseball Glove \\
\hline Landry & 25 & $\begin{array}{l}\text { Business } \\
\text { Administration }\end{array}$ & Junior & Baseball & $\begin{array}{l}\text { Poster of Buster } \\
\text { Douglas }\end{array}$ \\
\hline Lance & 21 & Mathematics & Junior & Baseball & Family Picture \\
\hline
\end{tabular}




\section{Data Collection and Analysis}

Participants were asked to identify an artifact that they considered to be something that has contributed to their academic motivation at the MSHBC. The participants had no limitations or restrictions on their artifact. Once the artifact was selected, participants were asked to meet individually with the lead researcher to briefly describe their chosen artifact and why they considered it to be influential to their academic persistence. Table 1 provides a summary of each participants' chosen artifact. The reason given by each participant for selecting his respective artifact were transcribed and coded. The lead researcher used line-by-line coding to identify codes related to the artifacts. Merriam (2009) describes coding as assigning a shorthand designation to various aspects of the data so that it can be easily retrieved. Similarities between codes were identified, resulting in codes being aggregated together into larger themes. Specifically, three themes emerged from this process related to participants' discussion of their chosen artifacts: (a) family, (b) resilience, and (c) faith. The following section presents why the participants chose their artifacts. The findings are contextualized within SDT to provide theoretical underpinnings for participants' explanations.

\section{Subjectivity Statement}

Qualitative researchers bring many assumptions to their studies. If these assumptions remain unaddressed, they can negatively impact research outcomes. Therefore, it is essential that qualitative researchers state their assumptions and elaborate on their theoretical perspective (Merriam, 2009; Patton, 2002). Both researchers in this study were African American males who participated in competitive athletics throughout childhood and into their late teenage years. The lead researcher for this study, who did not participate in competitive athletics beyond high school, was motivated to graduate with a college degree by his deceased mother. His mother died of breast cancer when he was 12 years old and one of her major desires for him was to earn a college degree.

The second researcher for this study, who was a NCAA Division I football player, was motivated to earn a college degree by circumstance and his environment. He grew up as a recipient of free and reduced lunch and perceived that he lived in an area devoid of opportunity for personal and economic growth. He viewed higher education as a means to grow beyond the aforementioned circumstances. The second researcher was also motivated by family. Though he had the opportunity to play in the National Football League (NFL), he decided to complete a graduate degree after his final season of college athletics in order to model to his younger nephews and nieces how African Americans are capable of more than just participating in athletics.

\section{Results}

\section{Family}

SDT asserts that a sense of relatedness will facilitate intrinsic motivation (Deci \& Ryan, 2000). When asked to bring in an artifact that was representative of their academic motivation, three participants brought pictures of their family. These artifacts highlight the influence of relatedness to their self-motivation (Deci \& Ryan, 2000). First, Tinker brought an obituary and a 
picture of a deceased relative. When asked why he chose these artifacts and how they influenced his academic motivation, an emotional Tinker stated:

Well, these are two of my lil' cousins. They both passed away at a young age. These were my first cousins too, so we were real close. They looked up to me and my aunties would always tell me that they would be asking about me and how I'm doing in school. Cuz you know they were back home in [name of city]. Mane, it really hit me hard when they died though. I kinda fell off with my grades, wasn't eating right, you know. But I know they would have wanted me to do good, so I just keep this as a reminder as to why I'm doing what I'm doing. I know they are watching over me, so I just want to keep making them proud of me.

Like Tinker, Vince also brought an artifact pertaining to a deceased relative: his father. Vince's father died when he was eleven years old due to complications with sickle cell disease. Thereafter, he stayed with his cousin who legally adopted him and became his guardian. To this day, Vince carries a picture of his father in his wallet because: "I just keep him with me wherever I go. You know, it's like he watches over me." When asked to explain the picture and how it influences his academic motivation, Vince stated the following:

This is the last picture I ever took with my pops before he died. This one is just a copy that I had made, I think at Walgreens or something, a few years ago. I just keep this one folded up in my wallet so I take it wherever I go. The original one [picture] is in a frame at the house.

Lance, too, selected a picture of his family as his artifact. In doing so, he explained:

Well, for me, it's like family is everything. Like my mother - she is like my everything. She just like push me to be better than her and she's like always taken care of me. Then my dad, he's like pretty much the same. He didn't finish college either, so he like tell me to make sure I'm getting my education. Then you got my grandma. She went to college and like she graduated. So, like I'm trying to be like her. And like she an accountant so she's like well off. So, like we're all just very close. I know like - it's nothing they wouldn't do for me, so like I just try to make them proud of me.

\section{Resilience}

In addition to intrinsic factors, SDT suggests that individuals can also be motivated by extrinsic factors such as approval, rewards, and avoidance of shame (Deci \& Ryan, 2000; 2002). Specifically, an individual's sense of autonomy will be influenced by external sources that align with their values and interests. Three participants selected artifacts that insinuate extrinsic factors were a key influence on their academic motivation. First, Brian's chosen artifact was a set of military dog tags. When asked to explain their significance, he stated the following:

These dog tags say, "Don't let people make you feel bad for wanting to be better." I don't know where I first heard that from, but wherever I heard it, I liked it, so I 
used it. You know, this lil' saying says a lot to me. It's like for all the haters out there, you know that be trying to put you down and make you feel bad and stuff, and all you be trying to do is do you and do better. So, for me, I just wear it as like motivation. I'm here in school trying be about something and folks steady be trying to come at you sideways. So, I just keep doing me and let 'em hate.

Though Brian admitted the actual dog tags were more of a fashion statement than anything else, it was the inscription that he found motivating.

Likewise, Billy selected a baseball glove as his artifact. He revealed the baseball glove had dual meanings with respect to his academic motivation. First, the baseball glove served as a reminder that he needed to "catch [himself]" as he goes through life. More importantly, according to Billy, the baseball glove was a symbol of hope and opportunity:

But for real, I mean, baseball provided me this opportunity to even come to college. I might have still been in college without baseball, but baseball has always provided - like a consistent thing for me to do and work towards. So, like I know in order to play, I had to keep my grades up, so for me, it's just been that thing that has always been my reward for handling my business in the classroom.

Finally, Landry brought a poster of Buster Douglas in his famous boxing match against Mike Tyson. Buster Douglas, who was a 42-to-1 underdog in the fight, "shocked the world" in 1990 by recording a knockout victory against the then-undefeated and undisputed champion Mike Tyson. Landry elaborated on why he chose this artifact as motivation for his academic persistence:

I picked Buster Douglas against Mike Tyson because of the story that goes with this fight. Buster Douglas's mother told the world that her son was gonna beat Mike Tyson and two days before the fight his mother died. Buster Douglas had a choice to make - to either fight or let his legacy die with his mother. But here's why it was bigger than that. So, during the fight, Buster Douglas was knocked down by Mike Tyson but the bell saved Buster from being knocked out. Then the next round, Mike Tyson come out attacking him but Buster Douglas fought back, knocked out Mike Tyson, and won. And no one had ever got up from a Mike Tyson knock out.

Landry further expressed:

I feel like I'm the underdog. Like everybody counted me out, especially when I was down, they counted me out. But I'm a fighter, you know. I'mma get back up like Buster Douglas and show 'em something and I'mma knock they ass out. Not literally knock 'em out [laughter], but you know what I mean. I'm gonna win the fight.

The resiliency that Landry expressed in his determination to "win the fight," is symbolic of him winning in life and succeeding even when faced with adversity.

\section{Faith}


SDT posits that a sense of autonomy is a vital component to self-determined actions and motivation (Deci \& Ryan, 2000; 2002). One participant, Luke, was motivated by his Christian faith to achieve his life aspirations. Accordingly, he brought the King James version of the Bible as his artifact. Luke discussed his faith in God and disclosed how such faith was instilled in him. Luke said:

This [Bible] was given to me by my grandma when I was like in high school, like the $10^{\text {th }}$ or $11^{\text {th }}$ grade or something. I'm a Christian and my parents raised me to have faith in God. So, you know, I know I'm blessed cuz I know I could be doing a lot worse. I just graduated and I'm just blessed.

When asked how often he reads the Bible, Luke stated, "To be honest, not a whole lot. Not like I should. I know I should do better. I read a verse or two every now and then though for like motivation and stuff." However, he believed his life had purpose and that by obeying God's will, he would achieve this purpose.

\section{Discussion}

The purpose of the current study was to examine the experiences of African American male college athletes to ascertain the influences on their academic motivation and persistence. Rather than using the NCAA Division I level as the context of the study, we focused on individuals at a NCAA Division II HBCU. By doing so, this study answers the call of researchers to extend the literature on African American college athletes beyond the NCAA Division I PWI level (Harrison et al., 2015). Fundamentally, we found that primary determinants of motivation for participants were intrinsic and extrinsic, as demonstrated by their artifacts.

The connections made between the participants and their artifacts were not only emotional, they were also spiritual and motivational. Using SDT (Deci \& Ryan, 2000; 2002) as a theoretical foundation, the results demonstrated that (a) a sense of relatedness vis-à-vis family, (b) external sources that aligned with values and interests such as sports and the improbable triumph of Buster Douglas, and (c) a sense of autonomy vis-à-vis faith were primary influences on the intrinsic motivation of participants. This insight was gleaned from the innovative methodological design of our study. From a methodological standpoint, we showed how the use of artifacts in qualitative research - as opposed to relying exclusively on interviews and focus groups - can yield alternative perspectives, as "what people say" is quite different from "what people do" (Hodder, 1994, p. 113). This is an important contribution of the current work, as no studies that we could find have examined the experience of African American college athletes using such a methodological technique. 


\section{Relatedness}

SDT postulates that motivation will be enhanced when the basic need of relatedness is satisfied (Deci \& Ryan, 2000; 2002). Three participants referred to relatedness in the form of family support as a factor that facilitated their motivation and persistence. In particular, the memories of deceased relatives served as the impetus for the motivations of these participants, as they wanted to make their family members proud of their efforts and accomplishments. This finding is important, as it helps to build a more complete picture of the academic motivations of African American male college athletes. The importance of family on the academic motivations of African American male college athletes have been documented in other studies. Donnor (2006), for example, reported that the motivation of NCAA Division I African American football players was significantly shaped by the perspectives of their parents on education. Likewise, Harrison and colleagues (2015) found that NCAA Division I African American male athletes who were high academic achievers often cited how family members bolstered their motivation, particularly during times when they experienced amotivation. This study, which used a context beyond NCAA DI, suggests that family members are integral to the motivations of African American male athletes despite the institutional context.

\section{Autonomy}

SDT also suggests that a sense of autonomy is a vital component to self-determined actions and motivation (Deci \& Ryan, 2000; 2002). An individual's sense of autonomy can be influenced by external sources that align with his values and interests. The artifacts provided by three participants implied that extrinsic factors served as motivating influences for their academic persistence. Specifically, these artifacts reminded participants about the importance of being resilient in life. Landry, for example, saw himself as somewhat of an underdog just as Buster Douglas was in his fight against Mike Tyson. The Douglas poster reminded Landry that he needed to be resilient at MSHBC. The presence and importance of academic resiliency in African American male college athletes has elsewhere been documented in research on this demographic group (Fuller, 2017; Martin et al., 2010). For instance, Fuller (2017) found examples in which African American male college athletes were empowered, rather than discouraged, when faced with stigma, stereotypes, and discrimination in higher education settings. Likewise, participants in Martin et al.'s (2010) study were motivated by knowing that they were deemed a threat in society because they were educated and informed. Future research should continue to explore how extrinsic factors influence the academic resiliency of African American male college athletes.

The Christian faith was also a motivating factor for one participant. Land, Mixon, Butcher, and Harris (2014) found that spiritual and religious beliefs were critical to the success of African American male students. Likewise, participants in Fuller at al.'s study (2017) of African American male college athletes cited participation in campus religious organizations as integral to their development as leaders. Though the importance of religion in the African American community is well documented (Taylor, Chatters, \& Levin, 2003), there is a dearth of research that examines its role in the lived experiences of African American male college athletes. This is an area of inquiry that is ripe for examination and should be considered by future researchers. 


\section{Conclusions and Recommendations}

\section{Limitations}

It should be noted that this research is limited in a number of ways. This study was conducted at a single institution and with only seven participants. It is possible that the perspectives of these individuals are not representative of all African American male college athletes. Perhaps our findings would have been different if participants were selected from other institution types (e.g., PWIs, Ivy League, etc.). Future research should address this limitation by utilizing artifactual analysis at other institution types. Also, as artifacts in a cultural setting can change over time and can gain or lose their value, the meaning of artifacts is often intensely personal and subjective. If asked again to produce an artifact that contributed to their academic motivation, participants might select something completely different. Future research can address this limitation by employing a longitudinal approach whereby African American male college athletes are asked to provide an artifact periodically throughout their college experience. Finally, the scope of the case study is potentially limited as the data that were analyzed from interviews centered around the artifacts, rather than the artifacts themselves. Future research can use the aforementioned concatenation exploration (Stebbins, 2006) to expand the scope of this case study by situating it in a larger program of research.

\section{Scholarly Implications}

Limitations withstanding, this case study research has key implications for scholarship. First, this research demonstrates the importance of using innovative methodological techniques to investigate the intersection of higher education and athletics. Though qualitative methodologies such as interviews and focus groups are valuable in their own rights, "what people say" is often different from "what people do" (Hodder, 1994, p. 113). Thus, innovative techniques such as artifactual analysis or visual elicitation (Harrison \& Lawrence, 2003) should be considered and employed.

Furthermore, this case study also lends itself well to the beginning links of the concatenation exploration process (Stebbins, 2006). Concatenation exploration is a research methodology by which independent or interconnected case studies are used, similar to links in a chain, to develop new and novel concepts, ideas, and grounded theories (Stebbins, 2006). At its core, concatenation exploration is concerned with the development of thoughts, ideas, and grounded theories that are greater than the sum of the individual case studies (Stebbins, 2006). Initial cases in the concatenation process are used to guide future inquiries and therefore do not have to be generalizable to a larger population (Stebbins, 2006). This is because the future inquiries, being based on the initial cases, will result in more generalizable concepts and theories (Stebbins, 2006). Thus, future research utilizing similar participants and contexts (e.g., HBCU college athletes) can build upon the findings of this case study to develop a broader program of research. 


\section{Practical Implications}

The findings of this case study research can prove invaluable for educators and practitioners as well. The findings can be used to better equip higher education professionals who work with African American male college athletes. The following are just a few ways in which higher education professionals can apply the findings from this case study to practice.

Artifacts. As revealed in this study, physical artifacts can serve as a powerful motivator for individuals. Accordingly, academic advisors who work with African American male college athletes can encourage them to select artifacts that are personally meaningful. Whether it be a folded picture in a wallet or a poster on a wall, artifacts can provide a physical and tangible source of motivation for students. Academic advisors might simply need to recall a student's respective artifact when working with him/her to generate sufficient motivation to successfully accomplish the task at hand, such as preparing for an exam or writing a research paper. For example, Fuller and colleagues (2016) describe how one African American male was responsible for caring for his younger siblings in addition to his demanding schedule as a college student and track and field athlete. The student was quoted as saying "I don't have time to think about being tired. This is bigger than me...I'm the only example they have" (Fuller et al., 2016, p. 9). Perhaps a simple artifact such as a photo of his siblings could provide motivation for this student, as well as others, when he does in fact become tired.

Faculty, too, can use the motivating potential of artifacts in their course design. For example, faculty can create an assignment that require students to select an artifact from their personal lives, write about its importance and significance to them, and then discuss how the artifact potentially intersects with course content. Such an assignment would necessitate critical and analytical thinking as students are required to find an intersection between a Buster Douglas poster and anthropology, biology, or sociology course content.

Pre-collegiate workshops. Given that family was the most frequently cited source of motivation, the findings from this study, coupled with those of prior research (Donnor, 2006; Harrison et al., 2015), highlight the importance of pre-collegiate workshops and interventions for the parents and family members of African American college athletes. These pre-collegiate workshops should go beyond introducing the student and family to the athletic culture in order to educate the family on how they can be involved in the student's academic and athletic progression. As noted by Harrison et al. (2015), a collective of proactive and informed parents is critical to "facilitate the success of African American male athletes" (p. 89). Higher education professionals can assist in developing and facilitating such workshops, programs, and interventions. 


\section{References}

Agyemang, K., Berg, B. K., \& Fuller, R. D. (2018). Disrupting the disruptor: Perceptions as institutional maintenance work at the 1968 Olympic Games. Journal of Sport Management, 6, 567-580. doi: https://doi.org/10.1123/jsm.2017-0268

Blank, A. S., Sweeney, K., \& Fuller, R. D. (2014). Room for growth in professional sport: An examination of the factors affecting African-American attendance. Sport Marketing Quarterly, 23, 225.

Cokley, K. O. (2003). What do we know about the motivation of African American students? Challenging the "anti-intellectual" myth. Harvard Educational Review, 73, 524-558.

Cooper, J. N. (2013). A culture of collective uplift: The influence of a historically Black university/college on Black male student athletes' experiences. Journal of Issues in Intercollegiate Athletics, 6, 306-331.

Cooper, J. N., \& Hall, J. (2014). Understanding Black male student athletes' experiences at a historically Black college/university: A mixed methods approach. Journal of Mixed Methods Research, 1-18.

Cooper, J. N., \& Hawkins, B. (2012). A place of opportunity: Black male student athletes' experiences at a historically Black University. Journal of Intercollegiate Sport, 5, 170188.

Creswell, J. W. (2007). Qualitative inquiry \& research design: Choosing among five approaches $\left(2^{\text {nd }}\right.$ ed). Thousand Oaks, CA: Sage Publications.

Deci, E. L., \& Ryan, R. M. (2000). The "what" and "why" of goal pursuits: Human needs and the self-determination of behavior. Psychological Inquiry, 11, 227-268.

Deci, E. L., \& Ryan, R. M. (2002). Self-determination research: Reflections and future directions. In R. M. Ryan (Ed.), Handbook of self-determination research, (pp. 431-441). Rochester, NY: University of Rochester Press. 
Donnor, J. K. (2006). Parent(s): The biggest influence in the education of African American football student-athletes. In A. D. Dixson, \& C. K. Rousseau (Eds.), Critical race theory in education: All God's children got a song (pp.153-166). New York, NY: Routledge.

Eisenhardt, K. M. (1989). Building theories from case study research. Academy of Management Review, 14(4), 532-550.

Fuller, R. D. (2013). Race in pads and race in class? An examination of perceptions of stereotypes and racial discrimination among African American male college athletes. Journal for the Study of Sports and Athletes in Education, 7, 190 - 209.

Fuller, R. D. (2017). Perception or reality: The relationship between stereotypes, discrimination, and the academic outcomes of African American male college athletes. Journal of Sport and Social Issues, 41(5), 402-424.

Fuller, R. D., Harrison, C. K., Bukstein, S. J., Martin, B. E., Lawrence, S. M., \& Gadsby, P. (2016). That smart dude: A qualitative investigation of the African American scholarballer identity. Urban Education, doi: https://doi.org/10.1177/0042085916668955

Fuller, R. D., Lawrence, S. M., Harrison, C. K., Eyanson, J., \& Parks, C. (2017). The impact of high school on the leadership development of African American male scholar-athletes. The High School Journal, 100, 146-162.

Hagger, M. S., \& Chatzisarantis, N. L. (2007). Intrinsic motivation and self-determination in exercise and sport. Champaigne, IL: Human Kinetics.

Harrison, C. K., \& Lawrence, S. M. (2003). African American student athletes' perceptions of career transition in sport: A qualitative and visual elicitation. Race Ethnicity and Education, 6(4), 373-394.

Harrison, C. K., Martin, B. E., \& Fuller, R. (2015). “Eagles don’t fly with sparrows:” Selfdetermination theory, African American male scholar-athletes and peer group influences on motivation. The Journal of Negro Education, 84, 80-93.

Hodder, I. (1994). The interpretation of documents and materials. In N. K. Denzin \& Y. Lincoln (Eds.), Handbook of qualitative research (pp. 110-129). Thousand Oaks, CA: Sage. 
Land, A., Mixon, J. R., Butcher, J., \& Harris, S. (2014). Stories of six successful African American males high school students: A qualitative study. NASSP Bulletin, 98(2), 142162.

Martin, B. E., Harrison, C. K., Stone, J., \& Lawrence, S. M. (2010). Athletic voices and academic victories: African American male student-athlete experiences in the PAC-10. Journal of Sport \& Social Issues, 34, 131-153.

Merriam, S. B. (2009). Qualitative research: A guide to design and implementation. San Francisco, CA: Jossey-Bass.

Patton, M. Q. (2002). Qualitative research and evaluation methods. Thousand Oaks, CA: Sage.

Singer, J. N. (2005). Understanding racism through the eyes of African American male studentathletes. Race Ethnicity and Education, 8(4), 365-386.

Stebbins, R. A. (2006). Concatenated exploration: Aiding theoretic memory by planning well for the future. Journal of Contemporary Ethnography, 35(5), 483-494.

Taylor, R. J., Chatters, L. M., \& Levin, J. (2003). Religion in the lives of African Americans: Social, psychological, and health perspectives. Thousand Oaks, CA: Sage Publications. 